\title{
Liberal versus conservative oxygen therapy in critically ill patients: using the fragility index to determine robust results
}

\author{
Maria Vargas ${ }^{*}$ (D) and Giuseppe Servillo
}

Guidelines on the use of supplemental oxygen for various acute illnesses in adults are contradictory and inconsistent, and at this time no high-quality evidence base exists [1]. Although many randomized controlled trials (RCTs) comparing liberal versus conservative oxygen for various critical conditions have been done, the trial data are not conclusive [2]. With this in mind, we read with great interest the just published systematic review and meta-analysis by Chu et al. [2] on mortality and morbidity in acutely ill adults treated with liberal versus conservative oxygen therapy. The authors stated that liberal supplemental oxygen was harmful and associated with a dose-dependent increased risk of short-term and long-term mortality [2]. Chu et al. performed an excellent statistical analysis and a robust trial sequential analysis. Our major concern is about the fragility of the included trials. As we know from the current literature, RCTs are designed to assess objectively the safety and efficacy of a specific intervention [3]. Recently the fragility index (FI), an intuitive measure of the robustness of RCTs, was introduced in the critical care area [4]. Studies with larger FI values have more robust findings compared with the studies with poor FI values $[3,4]$. We evaluated the FI of the RCTs included in the meta-analysis by $\mathrm{Chu}$ et al. using a two-by-two contingency table and $p$ value produced by Fisher exact test [4]. Surprisingly, we found that 18 RCTs had a FI of 0 while the unpublished data from trial NCT00414726 had a FI of 2 (Table 1). Furthermore, we looked at the statistical significance of the mortality reported in the included study and found that only the study by Girardis et al. [5] reached statistical significance in the primary outcome.

The authors stated that their data may have potential implications in clinical practice of acutely ill patients. According to our results, critical care clinicians should be wary of basing decisions about conservative or liberal oxygen therapy on the available information from this meta-analysis [1] including trials with a low FI.

Furthermore, these results came from fragile and not statistically significant RCTs. Maybe it is time to add the FI and/or statistical significance of the considered outcome as criteria for the evaluation of the quality of evidence.

* Correspondence: vargas.maria82@gmail.com

Department of Neurosciences, Reproductive and Odontostomatological

Sciences, University of Naples "Federico II", via Pansini, 80100 Naples, Italy

(c) The Author(s). 2019 Open Access This article is distributed under the terms of the Creative Commons Attribution 4.0 International License (http://creativecommons.org/licenses/by/4.0/), which permits unrestricted use, distribution, and reproduction in any medium, provided you give appropriate credit to the original author(s) and the source, provide a link to the Creative Commons license, and indicate if changes were made. The Creative Commons Public Domain Dedication waiver (http://creativecommons.org/publicdomain/zero/1.0/) applies to the data made available in this article, unless otherwise stated. 
Table 1 Fragility index calculated for the study included in the systematic review and meta-analysis by Chu et al. [1]

\begin{tabular}{|c|c|c|c|c|c|}
\hline Study & Setting & $\begin{array}{l}\text { Liberal group } \\
\text { (FiO2 } 0.52 \text { Cl:0.39-0.85) }\end{array}$ & $\begin{array}{l}\text { Conservative group } \\
\text { (FiO2 } 0.21 \text { Cl:0.21-0.50) }\end{array}$ & $\begin{array}{l}p \text { value for mortality } \\
\text { in each study }\end{array}$ & Fragility index $n(p)$ \\
\hline Ali et al. (2014) [6] & Stroke & $5 / 155$ & $4 / 146$ & 0.99 & $0(1)$ \\
\hline Roffe et al. (2017) [7] & Stroke & $50 / 2668$ & $45 / 2668$ & 0.75 & $0(0.506)$ \\
\hline Ronning et al. (1999) [8] & Stroke & $36 / 292$ & $27 / 258$ & 0.54 & $0(0.506)$ \\
\hline Singhal et al. (2005) [9] & Stroke & $0 / 9$ & $1 / 7$ & NS & $0(0.438)$ \\
\hline NCT00414726 & Stroke & $14 / 43$ & $4 / 42$ & 0.08 & $2(0.072)$ \\
\hline Shi et al. (2017) [10] & Stroke & $0 / 9$ & $0 / 9$ & NS & $0(1)$ \\
\hline NCT02378454 (2015) & Sepsis & $3 / 25$ & $2 / 25$ & NS & $0(1)$ \\
\hline Butler et al. (1987) [11] & Limb ischemia & $1 / 17$ & $0 / 22$ & NS & $0(0.436)$ \\
\hline Schietroma et al. (2016) [12] & Perforated peptic ulcer & $2 / 119$ & $4 / 120$ & 0.42 & 0 (0648) \\
\hline NCT02687217 & Acute appendicitis & $0 / 30$ & $0 / 30$ & NS & $0(1)$ \\
\hline Girardis et al. (2016) [5] & Critical illness & $80 / 243$ & $58 / 235$ & 0.01 & $0(0.055)$ \\
\hline Panwar et al. (2016) [13] & Critical illness & $12 / 51$ & $13 / 53$ & 0.44 & $0(1)$ \\
\hline Hofmann et al. (2017) [14] & Myocardial infarction & $53 / 3311$ & $44 / 3318$ & 0.08 & $0(0.359)$ \\
\hline Khoshnood et al. (2015) [15] & Myocardial infarction & $3 / 85$ & $3 / 75$ & NS & $0(1)$ \\
\hline Kuisma et al. (2006) [16] & Cardiac arrest & $4 / 14$ & $4 / 14$ & NS & $0(1)$ \\
\hline Rawles et al. (1976) [17] & Myocardial infarction & $9 / 105$ & $3 / 95$ & NS & $0(0.140)$ \\
\hline Stub et al. (2012) [18] & Myocardial infarction & $5 / 132$ & $11 / 132$ & NS & $0(0.204)$ \\
\hline Ukholkina et al. (2005) [19] & Myocardial infarction & $1 / 58$ & $0 / 79$ & NS & $0(0.428)$ \\
\hline Young et al. (2014) [20] & Cardiac arrest & $5 / 9$ & $4 / 8$ & NS & $0(1)$ \\
\hline
\end{tabular}

NS not significant

\section{Abbreviations}

FI: Fragility index; RCTs: Randomized controlled trials

\section{Authors' contributions}

MV and GS analyzed and interpreted the data, wrote the paper, and approved the manuscript. Both authors read and approved the final manuscript.

\section{Ethics approval and consent to participate}

NA

\section{Consent for publication}

NA

\section{Competing interests}

The authors declare that they have no competing interests.

\section{Publisher's Note}

Springer Nature remains neutral with regard to jurisdictional claims in published maps and institutional affiliations.

\section{Received: 31 July 2018 Accepted: 23 August 2018}

\section{Published online: 18 April 2019}

\section{References}

1. O'Driscoll BR, Howard LS, Earis J, et al. British Thoracic Society guideline for oxygen use in adults in healthcare and emergency settings. Thorax. 2017; 72(suppl 1):ii1-90.

2. Chu DK, Kim LH, Young PJ, et al. Mortality and morbidity in acuyely ill adults treated with liberal versus conservative oxygen therapy (IOTA): a systemaic review and meta-analysis. Lancet. 2018;391:1693-705.

3. Walsh M, Srinathan SK, MCAuley DF, et al. The statistical significance of randomized controlled trial results is frequently fragile: a case for a fragility index. J Clin Epidemiol. 2014;67:622-8.
4. Ridgeon EE, Young PJ, Bellomo R, et al. The fragility index in multicenter randomized controlled critical care trials. Crit Care Med. 2016:44:1278-84.

5. Girardis M, Busani S, Damiani E, et al. Effect of conservative vs conventional oxygen therapy on mortality among patients in an intensive care unit: the oxygen-ICU randomized clinical trial. JAMA. 2016;316:1583-9.

6. Ali K, Warusevitane A, Lally F, et al. The stroke oxygen pilot study: a randomized controlled trial of the effects of routine oxygen supplementation early after acute stroke-effect on key outcomes at six months. PLoS One. 2014;8:e59274.

7. Roffe C, Nevatte T, Sim J, et al. Effect of routine low-dose oxygen supplementation on death and disability in adults with acute stroke: the stroke oxygen study randomized clinical trial. JAMA. 2017;318:1125-35.

8. Ronning OM, Guldvog B. Should stroke victims routinely receive supplemental oxygen? A quasi-randomized controlled trial. Stroke. 1999;30: 2033-7.

9. Singhal $A B$, Benner $T$, Roccatagliata $L$, et al. A pilot study of normobaric oxygen therapy in acute ischemic stroke. Stroke. 2005;36:797-802.

10. Shi S, Qi Z, Ma Q, et al. Normobaric hyperoxia reduces blood occludin fragments in rats and patients with acute ischemic stroke. Stroke. 2017;48: 2848-54.

11. Butler CM, Ham RO, Lafferty K, Cotton LT, Roberts VC. The effect of adjuvant oxygen therapy on transcutaneous pO2 and healing in the below-knee amputee. Prosthet Orthot Int. 1987;11:10-16.

12. Schietroma M, Cecilia EM, De Santis G, Carlei F, Pessia B, Amicucci G. Supplemental peri-operative oxygen and incision site infection after surgery for perforated peptic ulcer: a randomized, double-blind monocentric trial. Surg Infect. 2016;17:106-13.

13. Panwar R, Hardie M, Bellomo R, et al. Conservative versus liberal oxygenation targets for mechanically ventilated patients. A pilot multicenter randomized controlled trial. Am J Respir Crit Care Med. 2016;193:43-51.

14. Hofmann R, James SK, Jernberg T, et al. Oxygen therapy in suspected acute myocardial infarction. N Engl J Med. 2017;377:1240-9.

15. Khoshnood A, Carlsson M, Akbarzadeh M, et al. The effects of oxygen therapy on myocardial salvage in ST elevation myocardial infarction treated with acute percutaneous coronary intervention: the Supplemental Oxygen 
in Catheterized Coronary Emergency Reperfusion (SOCCER) study. Cardiology. 2015;132:16-21.

16. Kuisma M, Boyd J, Voipio V, Alaspaa A, Roine RO, Rosenberg P. Comparison of 30 and the $100 \%$ inspired oxygen concentrations during early postresuscitation period: a randomised controlled pilot study. Resuscitation. 2006;69:199-20.

17. Rawles JM, Kenmure AC. Controlled trial of oxygen in uncomplicated myocardial infarction. BMJ. 1976;1:1121-23.

18. Stub D, Smith K, Bernard S, et al. A randomized controlled trial of oxygen therapy in acute myocardial infarction Air Verses Oxygen In myocarDial infarction study (AVOID Study). Am Heart J. 2012;163:339-45.e1.

19. Ukholkina GB, Kostianov II, Kuchkina NV, Grendo EP, Gofman IB. Oxygen therapy in combination with endovascular reperfusion during the first hours of acute myocardial infarction: clinical and laboratory findings. Int I Interv Cardioangiol. 2005;9:45-51.

20. Young P, Bailey M, Bellomo R, et al. HyperOxic Therapy OR NormOxic Therapy after out-of-hospital cardiac arrest (HOT OR NOT): a randomised controlled feasibility trial. Resuscitation. 2014;85:1686-91. 